\title{
Extraction and Determination of Oxymatrine Pesticide in Environmental Sample and in its Formulation using High-Performance Liquid Chromatography
}

\author{
Ihsan M. Shaheed ${ }^{1}$ and Saadiyah A. Dhahir ${ }^{2}$ \\ ${ }^{1}$ Department of Chemistry, Faculty of Science, University of Baghdad, \\ Baghdad, Iraq \\ ${ }^{2}$ Department of Chemistry, Faculty of Science for Women, University of Baghdad, \\ Baghdad, Iraq
}

\begin{abstract}
The quinolizindine alkaloid compound, oxymatrine pesticide, was analysis in the river water samples collected from different agriculture areas in the Iraqi city of Kerbala and also in its formulation using developed reverse-phase high-performance liquid chromatography method. Acetonitrile:methanol (60:40 v/v) was chosen as mobile phase at $\mathrm{pH}(7.0)$, flow rate $0.5 \mathrm{~mL} / \mathrm{min}$, and $20 \mu \mathrm{L}$ as volume injection. Modified ecological-friendly method, dispersive liquid-liquid microextraction, was used for the extraction of oxymatrine from water samples. Linearity study was constructed from 0.1 to $70 \mu \mathrm{g} / \mathrm{mL}$ at $\lambda_{\max } 205 \mathrm{~nm}$. The limit of detection and limit of quantification were 0.025 and $0.082 \mu \mathrm{g} / \mathrm{mL}$, respectively, and the relative standard deviation (RSD) \% was $0.518 \%$. Three spiked levels of concentration $(20.0,40.0$, and $70.0 \mu \mathrm{g} / \mathrm{mL})$ were used for the validation method. The percentage recovery for the three spiked samples was ranged between 98.743 and 99.432 and the RSD\% was between 0.051 and $0.202 \%$, the formulation studies of oxymatrine between 99.487 and 99.798 , and the RSD\% was ranged from 0.045 to $0.057 \%$. The developed method can be used accurately and selectively for the determination of oxymatrine in environmental samples and in the formulation.
\end{abstract}

Index Terms - Dispersive, Oxymatrine, Reverse-phase highperformance liquid chromatography, UV visible.

\section{INTRODUCTION}

Alkaloids are compound which have low molecular weight which consist of nitrogen atom in its structure. Quinolizindine alkaloids are a type which can be found in $20 \%$ of plants. These quinolizindine alkaloids play an important role as a pesticides and in biological activity as starting material

ARO-The Scientific Journal of Koya University

Vol. VIII, No.2 (2020), Article ID: ARO.10666, 7 pages

DOI: $10.14500 /$ aro. 10666

Received 22 April 2020; Accepted 06 July 2020

Regular research paper: Published 01 September 2020

Corresponding author's e-mail: Ihsan.aldahan@uokerbala.edu.iq Copyright (C) 2020 Ihsan M. Shaheed and Saadiyah A. Dhahir. This is an open-access article distributed under the Creative Commons Attribution License. instead of acetylcholine to treat senile dementia due to its binding to cholinergic receptors called nicotinic and muscarinic respecters (John, et al., 2014).

Oxymatrine, tetracycloquinolizindine (7aS,13aR,13bR,13cS) dodecahydro-1H,5H,10H-dipyrido[2,1-f:3',2', 1'-ij][1,6] naphthyridin-10-one 4-oxide, as shown in Fig. 1, is a new extracted insecticide from the roots of Sophora flavescens Aiton which used as Chinese herbal to treat cooling and as an antichloristic (Li and Wang, 2004). Oxymatrine regarded as a new biopesticide, under the name Levo2.4, instead of chemical pesticides to overcome the aggregation of residual in environment (Gu, et al., 2012; Zhang, et al., 2015a; Gholam and Sadeghi, 2016). Patient who suffers from hepatitis B can sever form liver damage when they exposed to high dose of oxymatrine (Izdebska, et al., 2019).

Many techniques were reported for the analysis and determination of oxymatrine in plant as residual and in pharmaceutical preparations. Several techniques were used for the determination of oxymatrine, some of these techniques are high-performance liquid chromatography (HPLC) (Izdebska, et al., 2019; Bao, et al., 2019; Zhang, et al., 2016), liquid chromatography-mass spectroscopy (Zhang, et al., 2008; Fan, et al., 2013; Sabatino, et al., 2015; Jong, et al., 2006), capillary electrophoresis (Chen, et al., 2009; Zhang and Chen, 2013), flow injection (Cheng, et al., 2004), and microwaveassisted aqueous two-phase extraction (Zhang, et al., 2015b).

The aim of this study is to provide accurate, selective, and rapid method to the determined of oxymatrine in water samples and in its formulations used in agriculture areas under study because there is no such study which was reported in those areas for the determination of oxymatrine in spite of using this pesticide widely and repeatedly in those areas.

\section{Materials AND Methodologies}

\section{A. Reagent and Solutions}

Oxymatrine standard (purity $>99 \%$ ) was purchased from Dr. Ehrenstorfer GmbH Company. All solvents (methanol, 


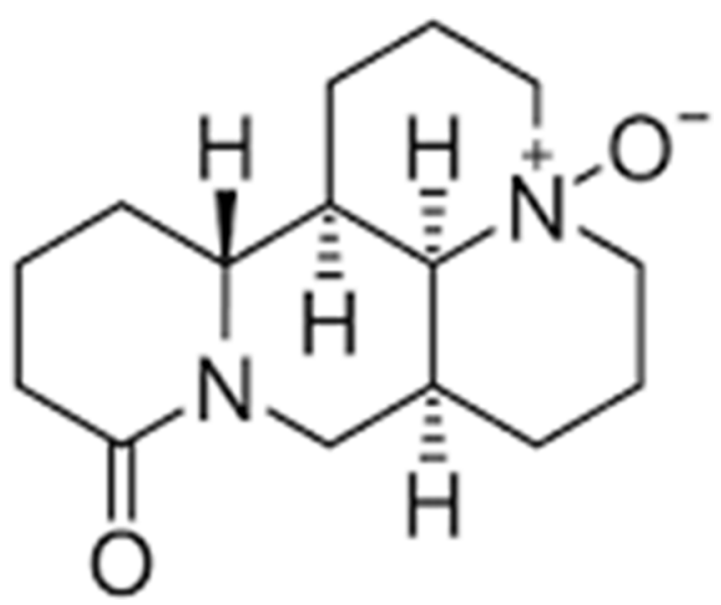

Fig. 1. Structure of oxymatrine.

acetonitrile, and water) for HPLC analysis were used from Sigma-Aldridge Company. Oxymatrine formulation (Levo2.4\%) was supplied from Karbala Agriculture Department, Iraq.

\section{B. Preparation of Standard Solutions}

Oxymatrine stock standard solution $1000 \mu \mathrm{g} / \mathrm{mL}$ was prepared by dissolving $0.1 \mathrm{~g}$ in methanol with sonication and completed to the mark in $100 \mathrm{~mL}$ volumetric flask, then filtered through $0.45 \mu \mathrm{m}$ Millipore filter. A series of solutions ranged from 0.1 to $200 \mu \mathrm{g} / \mathrm{mL}$ were prepared for calibration study. All solutions kept in $4^{\circ} \mathrm{C}$ until the time of analysis.

\section{Preparation of Oxymatrine Formulation}

A $1.0 \mathrm{~mL}$ of oxymatrine formulation (Levo 2.4\%) was diluted to $100 \mathrm{~mL}$, form this solution, further $1.0 \mathrm{~mL}$ was diluted to $100 \mathrm{~mL}$, from the final solution, a different concentrations of formulation were prepared by diluting the calculated volumes of solution in $100 \mathrm{~mL}$ methanol.

\section{Preparation of Sodium Hydroxide $0.1 \mathrm{M}$}

Sodium hydroxide $0.1 \mathrm{M}$ was prepared by dissolving $0.4 \mathrm{~g}$ in distilled water, then completed to $100 \mathrm{~mL}$ volumetric flask.

\section{E. Preparation of Orthophosphoric Acid $0.1 \mathrm{M}$}

Orthophosphoric acid was prepared by diluting $0.680 \mathrm{~mL}$ of concentrated orthophosphoric acid in distilled and completed the volume to $100 \mathrm{~mL}$ volumetric flask.

\section{F. Preparation of Sodium Chloride (5\%)}

A $5.0 \mathrm{~g}$ of sodium chloride was dissolved in distilled water and completed to the mark in $100 \mathrm{~mL}$ volumetric flask.

\section{SAMPLING}

Water samples were collected from agriculture ears in Iraqi city - Kerbala at six different locations: Site I (Center of Kerbala), two agriculture eras were chosen (Al-Kadhy -8 and Al-Kamaliyah), site II (Al-Hindyia), two locations chosen (South and North Al-Manfahan), and from site III (Al-
Khairat), two locations (Abu-Ruwayah and Zubaid) were collected chosen, then samples were transported in dark amber glass bottles to the laboratory under cooling conditions $\left(4^{\circ} \mathrm{C}\right)$. All samples were filtered through $0.45 \mu \mathrm{m}$ Nylon filter (Millipore filter) to remove any suspended particles or matrix in water samples, then the samples were stored at $4^{\circ} \mathrm{C}$ in the dark until the time of analysis.

\section{Modified Dispersive Liquid-Liquid MicroeXtraction}

A $5.0 \mathrm{~mL}$ from each water samples collected from different agriculture areas in Kerbala city, Iraq (reserved in standard conservation condition) were filtered and the supernatants were separated and transferred to a glass centrifuge test tube with screw. Each sample spiked with different concentration of oxymatrine standard $(20.0,40.0$, and $60.0 \mu \mathrm{g} / \mathrm{mL})$. Sodium chloride $(5 \%)$ was added as salting-out agent, then a mixture of $100 \mu \mathrm{L}$ chloroform, as dispersant agent, and $1.0 \mathrm{~mL}$ acetonitrile, as extraction solvent, were added, respectively. The final solution was vortexed for $1.0 \mathrm{~min}$ and further $10.0 \mathrm{~min}$ shaking by hand, then centrifuged at $5000 \mathrm{rpm}$ for $15.0 \mathrm{~min}$. Two phases will have separated; upper aqueous phase removed by microsyringe and organic phase contain extracted oxymatrine as fine droplets diluted with $2.0 \mathrm{~mL}$ methanol for HPLC analysis after filtration through $0.45 \mu \mathrm{m}$ Millipore filter paper. Same procedure was maintained for water samples collected from different agriculture areas for Kerbala city, Iraq, without spiking to use as controller (Albaseera, et al., 2011).

\section{INSTRUMENTATION}

HPLC 20A equipped with UV-visible detector. Ultrasonic cleaner with heating controller, KQ200E. Shimadzu doublebeam UV-spectrophotometer-1800. Digital balance, DenverTP-214. pH meter, Hanna-pH211. Centrifuge, C2series.

\section{Method Validation}

\section{A. Wavelength Selection}

From the stock solution of standard oxymatrine, $20.0 \mu \mathrm{g} / \mathrm{mL}$ solution was prepared for UV-visible scanning from 190 to $800 \mathrm{~nm}$. It was found that standard oxymatrine has maximum absorption at 205 nm, Fig. 2.

\section{B. Chromatographic Conditions}

Analysis of oxymatrine in samples and formulation was applied using HPLC supplied with ODS-C18 column $(250 \mathrm{~cm} \times 4.6 \mathrm{~mm}, 5 \mu \mathrm{m})$ and $\mathrm{UV}$-visible detector. The mobile phase was acetonitrile:methanol (60:40 v/v) at $\mathrm{pH}(7)$. The flow rate was $0.5 \mathrm{~mL} / \mathrm{min}$ and the volume of injection was $20.0 \mu \mathrm{L}$. The measurements were maintained at $205 \mathrm{~nm}$.

\section{Results AND Discussion}

\section{A. Preliminary Study}

Different composition of solvents was tested as mobile phase for the best separation, good resolution, and acceptable 
peak shape. Acetonitrile, methanol, and water are used alone and as a mixture with composition from 90:10 v/v to $50: 50 \mathrm{v} / \mathrm{v}$ to achieve an acceptable separation, Fig. 3. The mobile phase with the ratio $(60: 40 \mathrm{v} / \mathrm{v})$ was chosen for optimization due to the best separation and high response. All investigations were being under flow rate $1 \mathrm{~mL} / \mathrm{min}$ and volume injection $20.0 \mu \mathrm{L}$ at $\lambda_{\max } 205 \mathrm{~nm}$. Chromatogram for blank, Fig. 4, was explained for comparison with chromatogram of oxymatrine standard.

\section{B. Effect of $p H$}

Mobile phase was buffered with different $\mathrm{pH}$ to improve the peak shape and efficiency of alkaloid (oxymatrine) separation, for that, selected mobile phase (acetonitrile:methanol 60:40 $\mathrm{v} / \mathrm{v}$ ) was eluted under $\mathrm{pH}$ ranged from 3.0 to 8.0 using $0.1 \mathrm{M} \mathrm{H}_{3} \mathrm{PO}_{4}$ /and or $0.1 \mathrm{M} \mathrm{NaOH}$ for adjusting. Results obtained were illustrated in Table 1 and Fig. 5 for standard oxymatrine under optimized condition $(\mathrm{pH}=7.0)$. In general, oxymatrine regarded as weak basic and its protonation can be altered in acidic and basic media, it was found that $\mathrm{pH} 7.0$ was the best media for its separation.
Results in Table 1 and Fig. 5 explained that the separation of oxymatrine in acidic medium or high basic medium gave low intensity than in neutral medium depends on the properties of oxymatrine, for that $\mathrm{pH}$ (7.0) was chosen for optimization due to good resolution and acceptable values of capacity and tailing factors.

\section{Effect of Flow Rate}

A $20.0 \mu \mathrm{L}$ of $20.0 \mu \mathrm{g} / \mathrm{mL}$ oxymatrine standard at $\mathrm{pH}$ (7.0) was injected to HPLC system $(n=3)$ at various flow rates ranged from 0.3 to $1.5 \mathrm{~mL} / \mathrm{min}$.

TABLE I

EFFECT OF PH

\begin{tabular}{lcccc}
\hline \hline $\mathrm{pH}$ & Peak area & Resolution (R) & Capacity (k) & Tailing factor (TF) \\
\hline 3.0 & 18,544 & 20.897 & 2.260 & 1.122 \\
4.0 & 17,499 & 18.560 & 1.645 & 1.134 \\
5.0 & 20,270 & 20.943 & 2.230 & 1.124 \\
6.0 & 23,251 & 20.232 & 2.133 & 1.031 \\
7.0 & 25,960 & 13.051 & 1.231 & 1.041 \\
8.0 & 22,132 & 17.238 & 1.521 & 1.105 \\
\hline \hline
\end{tabular}

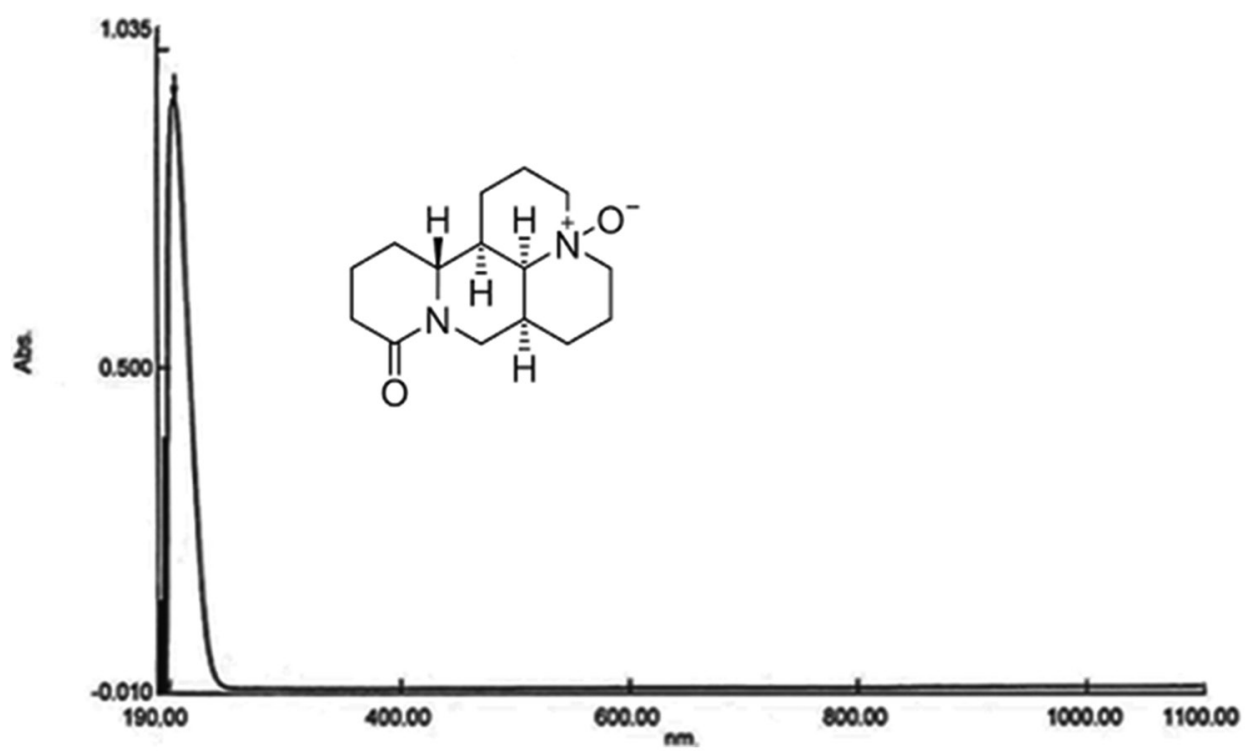

Fig. 2. UV-visible spectra for standard oxymatrine.

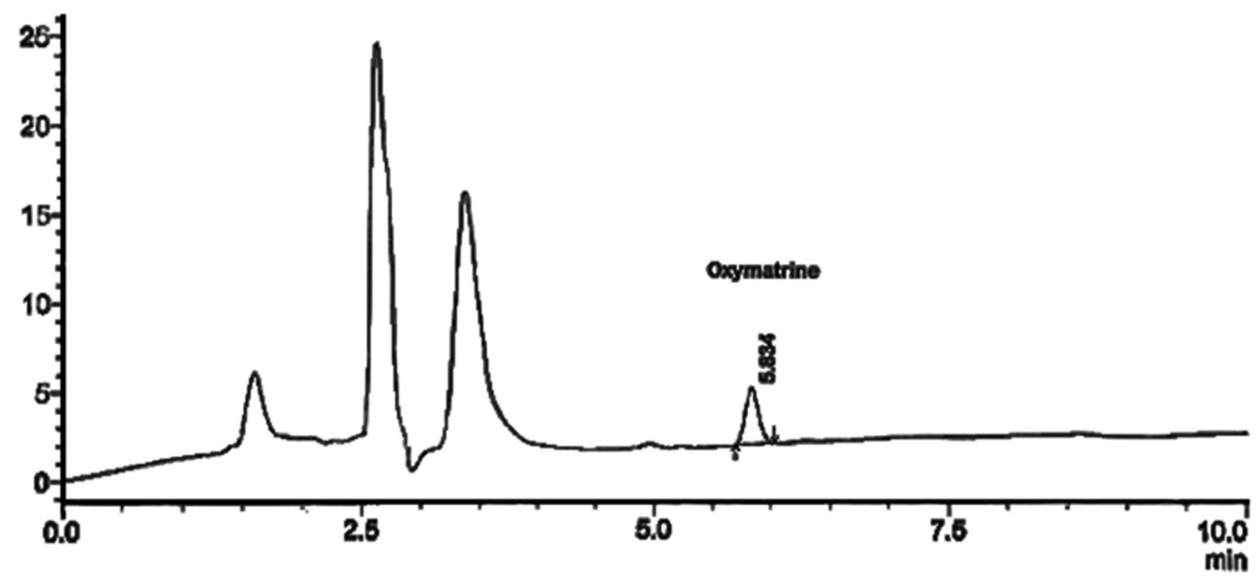

Fig. 3. Chromatogram of oxymatrine standard. 


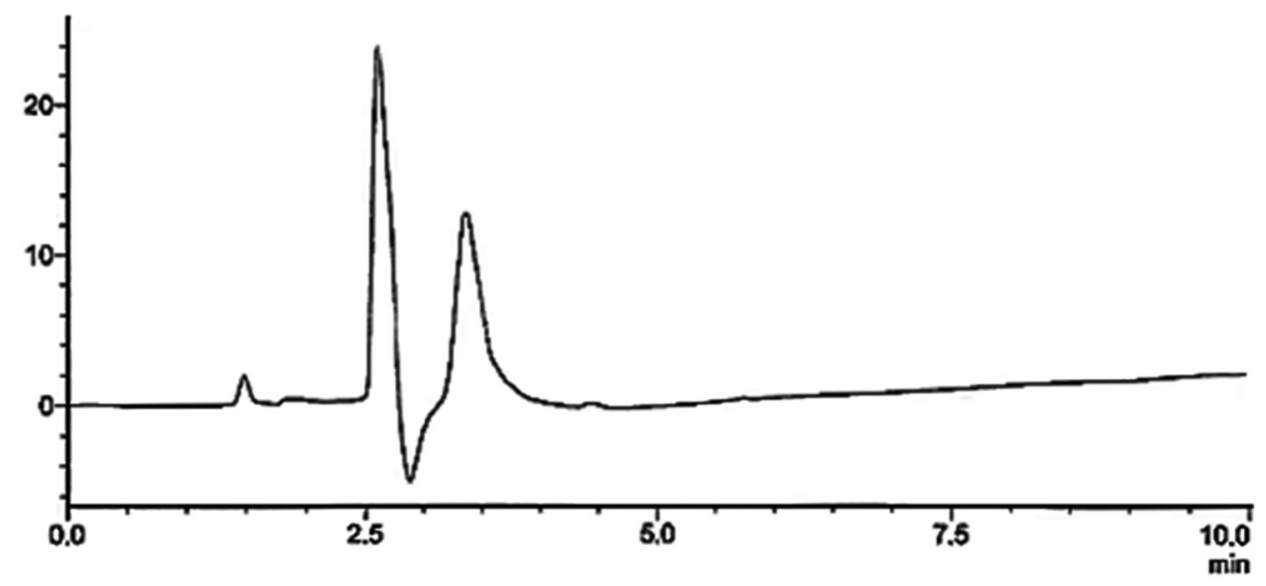

Fig. 4. Chromatogram of Blank.

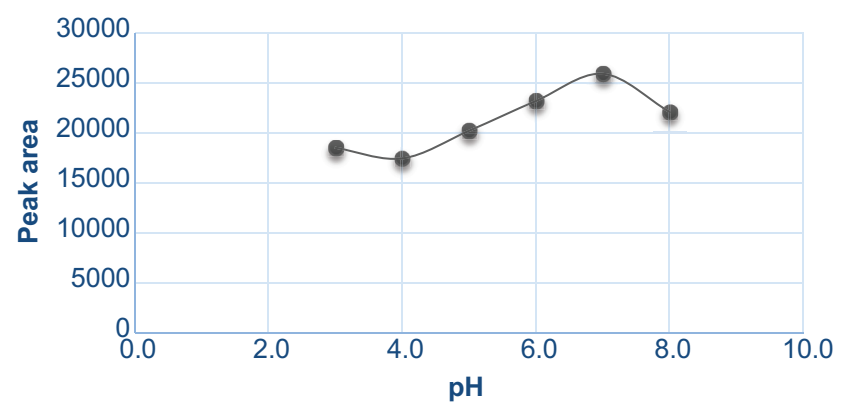

Fig. 5. Effect of $\mathrm{pH}$.

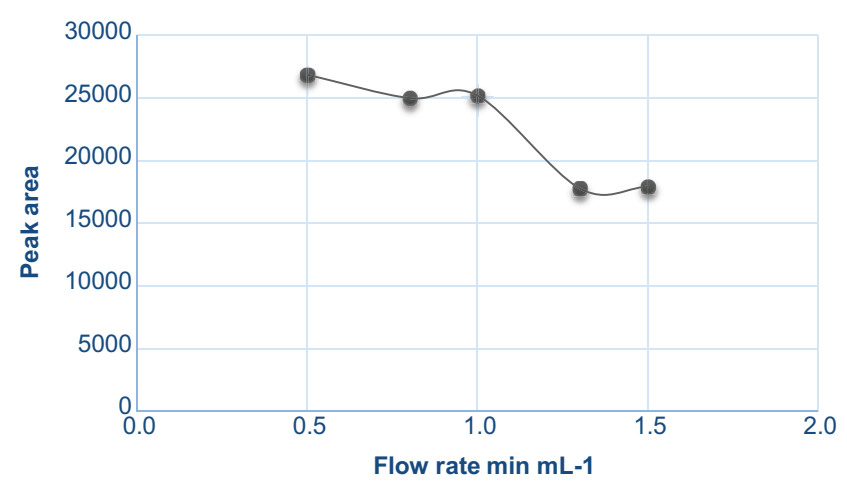

Fig. 6. Effect of flow rate.

Injection of oxymatrine standard into HPLC system at different flow rate explained that at $0.3 \mathrm{~mL} / \mathrm{min}$ too long time for analysis was required (Table 2 and Fig. 6). Flow rate at $0.5 \mathrm{~mL} / \mathrm{min}$ maintained high response with good capacity factor and low tailing factor after that the response decreases up to $1.5 \mathrm{~mL} / \mathrm{min}$. For that, $0.5 \mathrm{~mL} / \mathrm{min}$ was chosen for oxymatrine determination.

\section{Effect of Volume Injection}

A $20.0 \mu \mathrm{L}$ of $20.0 \mu \mathrm{g} / \mathrm{mL}$ of oxymatrine standard under optimized conditions of $\mathrm{pH}$ and flow rate was injected $(\mathrm{n}=3)$ to achieve the best separation.

From results shown in Table 3 and Fig. 7, increasing the injected volume of oxymatrine standard up to $20.0 \mu \mathrm{L}$ led
TABLE II

EFFECT OF FLOW RATE

\begin{tabular}{lcccc}
\hline \hline $\begin{array}{l}\text { Flow rate } \\
\mathrm{mL} / \mathrm{min}\end{array}$ & Peak area & $\begin{array}{c}\text { Resolution } \\
(\mathrm{R})\end{array}$ & Capacity & $\begin{array}{c}\text { Tailing } \\
\text { factor (TF) }\end{array}$ \\
\hline 0.3 & & \multicolumn{2}{c}{ No detection till $20 \mathrm{~min}$} & \\
0.5 & 26,048 & 10.643 & 2.963 & 1.123 \\
0.8 & 25,001 & 9.953 & 2.787 & 1.129 \\
1.0 & 25,193 & 8.983 & 1.196 & 1.135 \\
1.3 & 17,783 & 8.179 & 1.614 & 1.152 \\
1.5 & 17,931 & 7.421 & 1.648 & 1.182 \\
\hline \hline
\end{tabular}

TABLE III

EFFECT OF VOLUME INJECTION

\begin{tabular}{lcccc}
\hline \hline $\begin{array}{l}\text { Volume injection } \\
(\mu \mathrm{L})\end{array}$ & Area & $\begin{array}{c}\text { Resolution } \\
(\mathrm{R})\end{array}$ & Capacity (k) & $\begin{array}{c}\text { Tailing factor } \\
(\mathrm{TF})\end{array}$ \\
\hline 5 & 9502 & 9.117 & 3.061 & 1.100 \\
10 & 15,348 & 9.043 & 3.008 & 1.132 \\
15 & 20,771 & 8.681 & 2.993 & 1.119 \\
20 & 26,855 & 10.643 & 2.963 & 1.023 \\
\hline \hline
\end{tabular}

TABLE IV

Statistical Data Analysis of Determination of Oxymatrine

\begin{tabular}{|c|c|}
\hline Parameter & Results \\
\hline$\overline{\lambda \max (\mathrm{nm})}$ & 205 \\
\hline Correlation coefficient & 0.9999 \\
\hline Linearity range $(\mu \mathrm{g} / \mathrm{mL})$ & $0.1-70$ \\
\hline Limit of detection ${ }^{\mathrm{a}}(\mu \mathrm{g} / \mathrm{mL})$ & 0.024 \\
\hline Limit of quantification $(\mu \mathrm{g} / \mathrm{mL})$ & 0.082 \\
\hline Regression equation & $y=1219.6 x+1853.1$ \\
\hline Slope & 1219.6 \\
\hline Recovery \% & $100.002 \%$ \\
\hline $\mathrm{RSD} \%$ & 0.518 \\
\hline C. $\mathrm{L}^{\mathrm{c}}$ for $0.5 \mu \mathrm{g} / \mathrm{mL}$ & $0.498 \pm 0.004$ \\
\hline C.L for $10.0 \mu \mathrm{g} / \mathrm{mL}$ & $10.134 \pm 0.013$ \\
\hline C.L for $50.0 \mu \mathrm{g} / \mathrm{mL}$ & $49.757 \pm 0.020$ \\
\hline
\end{tabular}

to increase the response systematically without overloaded of the column and without affecting the capacity factor of the shape of chromatogram. 


\section{E. Linearity Curve}

A series of solution with different concentration ranged from 0.1 to $200 \mu \mathrm{g} / \mathrm{mL}$ were prepared for the calibration study at optimized conditions. The calibration curve obtained by plotting the peak area of injected solutions $(n=3)$ against the concentration. Linearity was achieved in the range from 0.1 to $70 \mu \mathrm{g} / \mathrm{mL}$, Fig. 8, after that increasing the concentration led to deviation from Beer's low. All results related to calibration curve study are sorted in Table 4.

\section{VALIDATION Method}

Validation of method was a proved in term of accuracy and precision. Accuracy was represented by recovery percentage

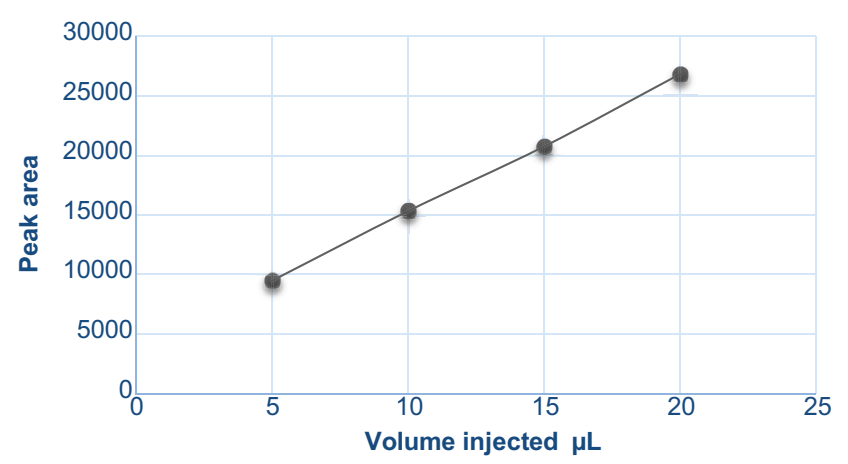

Fig. 7. Effect of volume injection.

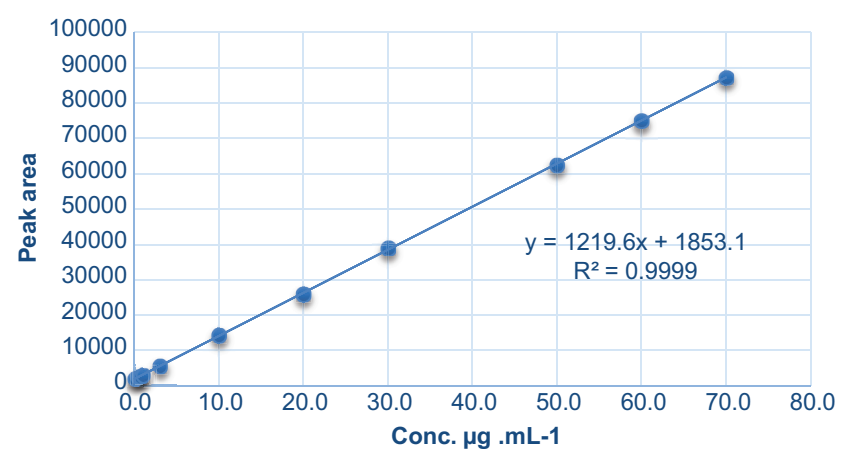

Fig. 8. Calibration curve of oxymatrine. value and precision by relative standard deviation (RSD) \%. Three different concentrations of prepared oxymatrine standards were injected $(n=5)$ into HPLC system under optimized condition for validation studies. Results are illustrated in Table 5.

\section{Applications}

The proposed method was applied for the determination of oxymatrine in spiked water samples with different concentration and also its formulation. The results are shown in Tables 6, 7 and Figs. 9-13. Values of recoveries (98.745-99.432) and RSD\% (0.202-0.064) obtained for the determination of oxymatrine in spiked water samples in addition to the acceptable values of recovery and $\mathrm{RSD} \%$ for oxymatrine in its formulation approved that the method was prices and accurate.

Results in Tables 6, 7 and Figs. 9, 10 explained that the applied method was accurate and selective for the

TABLE V

Accuracy and Precision of Determination of Oxymatrine Standars

\begin{tabular}{lccc}
\hline \hline Concentration $(\mu \mathrm{g} / \mathrm{mL})$ & $\begin{array}{c}\text { Found } \\
(\mu \mathrm{g} / \mathrm{mL})(\mathrm{n}=5)\end{array}$ & $\begin{array}{c}\text { Recovery\% } \\
(\mathrm{n}=5)\end{array}$ & $\begin{array}{c}\text { RSD\% } \\
(\mathrm{n}=5)\end{array}$ \\
\hline 0.5 & 0.465 & 93.096 & 0.698 \\
10.0 & 10.109 & 101.078 & 0.107 \\
50.0 & 49.752 & 99.505 & 0.033 \\
\hline \hline
\end{tabular}

TABLE VI

Determination of OXYMatrine In Spiked SAMPLes

\begin{tabular}{lccc}
\hline \hline $\begin{array}{l}\text { Added } \\
(\mu \mathrm{g} / \mathrm{mL})\end{array}$ & $\begin{array}{c}\text { Found }(\mu \mathrm{g} / \mathrm{mL}) \\
(\mathrm{n}=5)\end{array}$ & $\begin{array}{c}\text { Recovery \% } \\
(\mathrm{n}=5)\end{array}$ & $\begin{array}{c}\text { RSD\% } \\
(\mathrm{n}=5)\end{array}$ \\
\hline 20 & 19.748 & 98.745 & 0.202 \\
40 & 39.772 & 99.432 & 0.051 \\
70 & 69.236 & 98.908 & 0.064 \\
\hline \hline
\end{tabular}

TABLE VII

Determination OF OXYMATRINE IN Formulation

\begin{tabular}{lccc}
\hline \hline Added $(\mu \mathrm{g} / \mathrm{mL})$ & Found $(\mu \mathrm{g} / \mathrm{mL})$ & Recovery \% $(\mathrm{n}=5)$ & RSD $\%(\mathrm{n}=5)$ \\
\hline 30 & 29.846 & 99.487 & 0.057 \\
60 & 59.879 & 99.798 & 0.045 \\
\hline \hline
\end{tabular}

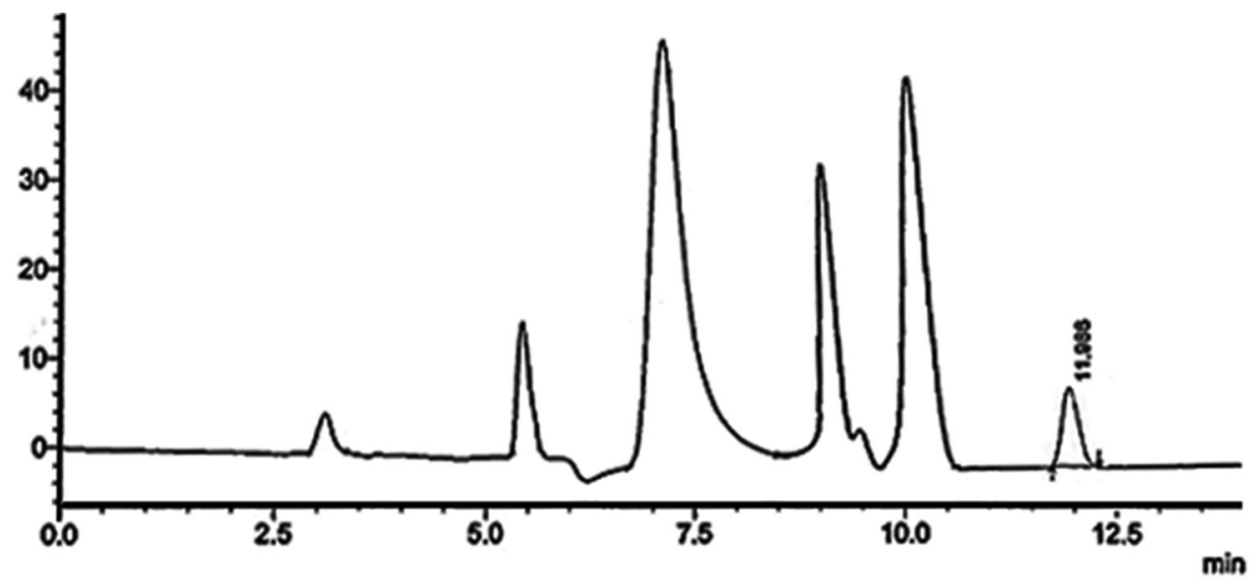

Fig. 9. Chromatograms for spiked water samples with $20.0 \mu \mathrm{g} / \mathrm{mL}$ oxymatrine. 


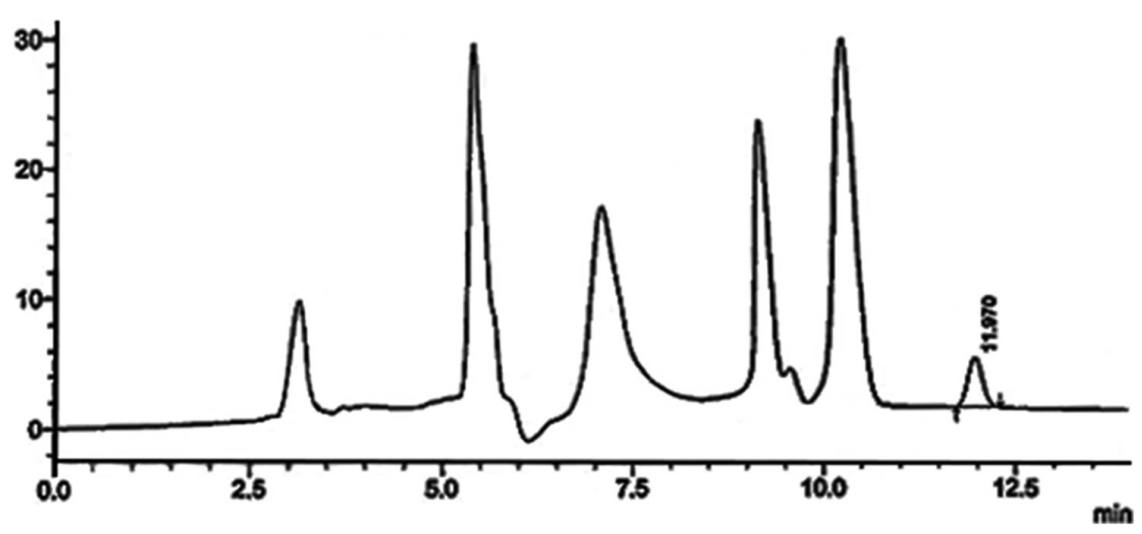

Fig. 10. Chromatograms for spiked water samples with $40 \mu \mathrm{g} / \mathrm{mL}$ oxymatrine.

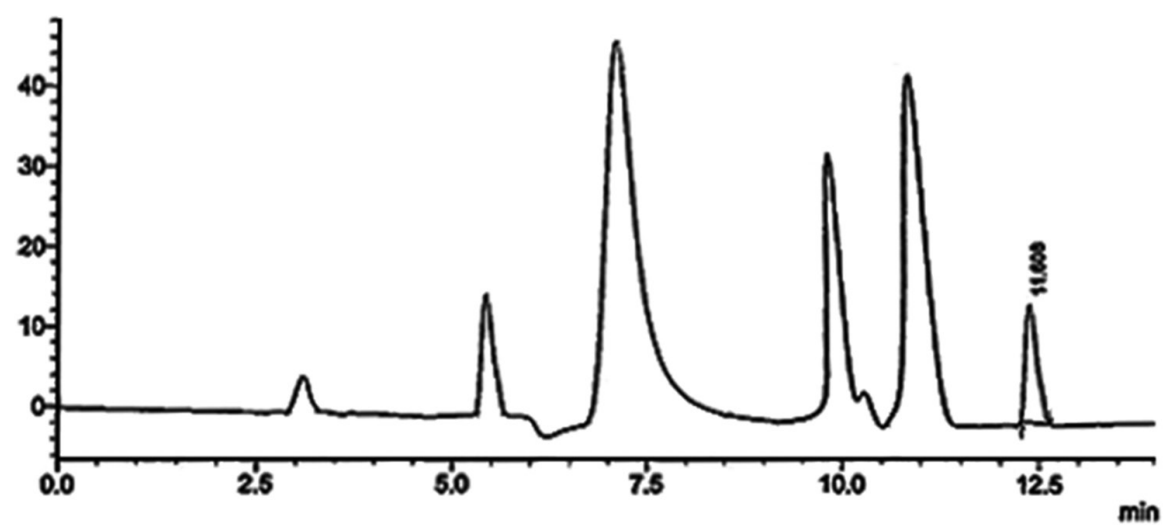

Fig. 11. Chromatograms for spiked water samples with $40.0 \mu \mathrm{g} / \mathrm{mL}$ oxymatrine.

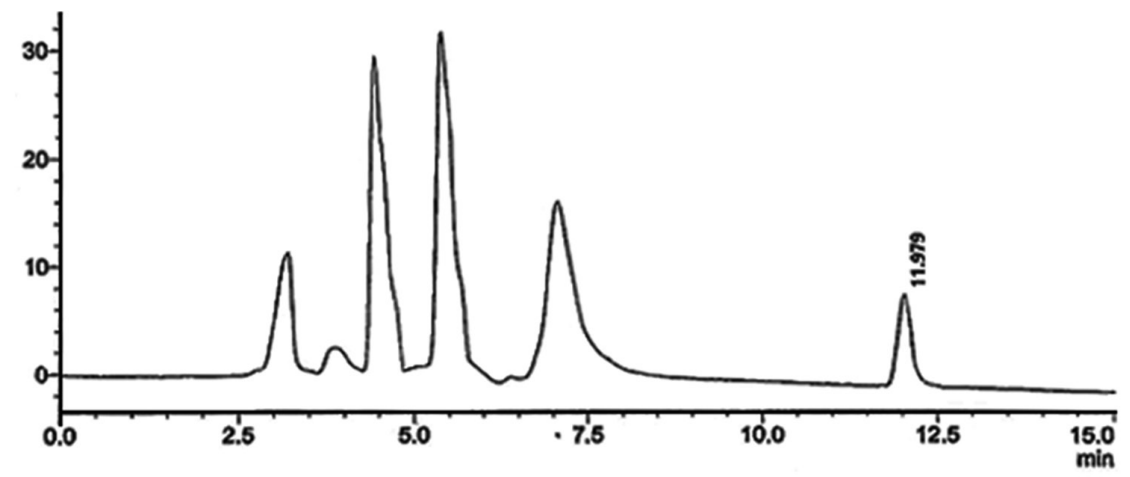

Fig. 12. Chromatograms for $30.0 \mu \mathrm{g} / \mathrm{mL}$ oxymatrine formulations.

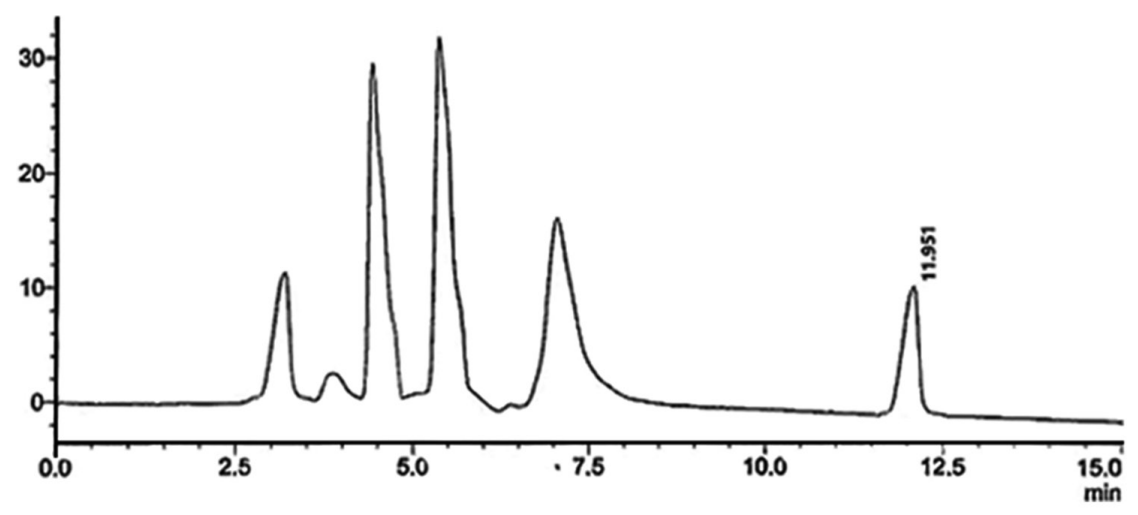

Fig. 13. Chromatograms for $60.0 \mu \mathrm{g} / \mathrm{mL}$ oxymatrine formulations. 
determination of oxymatrine in spiked water samples and formulation.

\section{CONCLUSION}

Although this pesticide is widely and repeatedly used in the treatment of crops in the regions from which the samples collected, which may cause the accumulation of oxymatrine in water samples, leading to influence farmers in those areas, the applied method explained that there is no high level of oxymatrine residual in all water samples collected from those different agriculture areas in Kerbala city, Iraq. On the other hand, high accuracy was obtained for the determination of oxymatrine in spiked water samples and also in the formulation of oxymatrine that used in the field, as a result this method can be used successfully to follow up oxymatrine residual in the environmental samples.

\section{ACKNOWLEDGMENT}

The authors are grateful for the facilities provided by department of chemistry, college of science for women and thank Kerbala department of agriculture, Iraq, for providing information about the agriculture area in which oxymatrine used as pesticides against insects.

\section{REFERENCES}

Albaseera, S.S., Raob, R.N., Swamyc, Y. and Mukkantia, K., 2011. Optimization of dispersive liquid liquid microextraction of pyrethroid insecticides from aqueous samples for determination by reversed-phase high performance liquid chromatography. Global Journal of Analytical Chemistry, 2(5), pp.224-231.

Bao, H., Chi, J., Yang, H., Liu, F., Fang, K. and Xu, Y., 2019. Simultaneous determination of six active components in danggui kushen pills via quantitative analysis of multicomponents by single marker. Journal of Analytical Methods in Chemistry, 2019, p.9620571.

Chen, Q., Li, P., Cheng, F., Li, B., Wu, S. and He, J., 2009. Nonaqueous CE for rapid and sensitive determination of matrine and oxymatrine in Sophora flavescens and its medicinal preparations. Chromatographia, 69, pp.1443-1446.

Cheng, Y., Chen, H., LI, Y., Chen, X. and Hu, Z., 2004. Separation and determination of aloperine, sophoridine, matrine and oxymatrine by combination of flow injection with microfluidic capillary electrophoresis. Talanta, 63, pp.491-496.

Fan, R., Liu, R., Ma, R., Bi, K. and Li, Q., 2013. Determination of oxymatrine and its active metabolite matrine in human plasma after administration of oxymatrine oral solution by high-performance liquid chromatography coupled with mass spectrometry. Fitoterapia, 89, pp.271-277.
Gholam, Z. and Sadeghi, A., 2016. Management strategies for western flower thrips in vegetable greenhouses in Iran: A review. Plant Protection Science, 52, pp.87-98.

Gu, X.B., Yang, X.J., Zhong, H., Lu, Z.H., Zhang, B., Zhu, Y.F., Wu, H.Y., Jiang, Y.M., Chen, H.K. and Hao, P., 2012. Effect of oxymatrine on specific cytotoxic T lymphocyte surface programmed death receptor-1 expression in patients with chronic hepatitis B. Chinese Medical Journal, 125, pp.1434-1438.

Izdebska, M., Zielińska, W., Hałas-Wiśniewska, M., Mikołajczyk, K. and Grzanka, A., 2019. The cytotoxic effect of oxymatrine on basic cellular processes of A549 non-small lung cancer cells. Acta Histochemica, 121, pp.724-731.

John, B., Sulaiman, C., George, S. and Reddy, V., 2014. Spectrophotometric estimation of total alkaloids in selected Justicia species. International Journal of Pharmacy and Pharmaceutical Sciences, 6, pp.647-648.

Jong, T.T., Lee, M.R., Chiang, Y.C. and Chiang, S.T., 2006. Using LC/MS/MS to determine matrine, oxymatrine, ferulic acid, mangiferin, and glycyrrhizin in the Chinese medicinal preparations Shiau-feng-saan and Dang-guei-nian-tong-tang. Journal of Pharmaceutical and Biomedical Analysis, 40, pp.472-477.

Li, J., Lin, D., J.I., R., Yao, K., Deng, W.Q., Yuan, H., Wu, Q., Jia, Q., Luo, P. and Zhou, K., 2016. Simultaneous determination of $\beta$-cypermethrin and its metabolite 3-phenoxybenzoic acid in microbial degradation systems by HPLC-UV. Journal of Chromatographic Science, 54, pp.1584-1592.

Li, K. and Wang, H., 2004. Simultaneous determination of matrine, sophoridine and oxymatrine in Sophora flavescens Ait. by high performance liquid chromatography. Biomedical Chromatography, 18, pp.178-182.

Sabatino, L., Scarangella, M., Lazzaro, F., Scordino, M., Picariello, G., Leotta, C., Traulo, P. and Gagliano, G., 2015. Matrine and oxymatrine in corroborant plant extracts and fertilizers: HPLC/MS-MS method development and singlelaboratory validation. Journal of Environmental Science and Health, Part B, 50, pp.862-870.

Zhang, J. and Chen, Z., 2013. Determination of matrine and oxymatrine in Sophora flavescens by nonaqueous capillary electrophoresis-electrospray ionization-ion trap-mass spectrometry. Analytical Letters, 46, pp.651-662.

Zhang, R., Hu, S., Chen, X. and Bai, X., 2016. Dispersive liquid liquid microextraction combined with high-performance liquid chromatography for the simultaneous analysis of matrine alkaloids in traditional Chinese medicine. Journal of Chromatographic Science, 54, pp.1687-1693.

Zhang, T.Z., Qiang, F., Tong, C. and Shi-Ping, M., 2015a. Anti-asthmatic effects of oxymatrine in a mouse model of allergic asthma through regulating CD40 signaling. Chinese Journal of Natural Medicines, 13, pp.368-374.

Zhang, W., Xiang, B.R. and Ma, P.C., 2008. Determination of oxymatrine in human plasma by LC-MS and study on its pharmacokinetics. Journal of Chromatographic Science, 46, pp.529-533.

Zhang, W., Zhu, D., Fan, H., Liu, X., Wan, Q., Wu, X., Liu, P. and Tang, J.Z., 2015b. Simultaneous extraction and purification of alkaloids from Sophora flavescens Ait. by microwave-assisted aqueous two-phase extraction with ethanol/ammonia sulfate system. Separation and Purification Technology, 141, pp.113-123. 